Article

\title{
Numerical Simulation on In-plane Deformation Characteristics of Lightweight Aluminum Honeycomb under Direct and Indirect Explosion
}

\author{
Xiangcheng Li $\odot$, Yuliang Lin * and Fangyun Lu \\ College of Liberal Arts and Science, National University of Defense Technology, Changsha 410073, China \\ * Correspondence: ansen_liang@163.com; Tel.: +86-138-0848-4146
}

Received: 6 June 2019; Accepted: 6 July 2019; Published: 10 July 2019

\begin{abstract}
Lightweight aluminum honeycomb is a buffering and energy-absorbed structure against dynamic impact and explosion. Direct and indirect explosions with different equivalent explosive masses are applied to investigate the in-plane deformation characteristics and energy-absorbing distribution of aluminum honeycombs. Two finite element models of honeycombs, i.e., rigid plate-honeycomb-rigid plate (RP-H-RP) and honeycomb-rigid plate (H-RP) are created. The models indicate that there are three deformation modes in the X1 direction for the RP-H-RP, which are the overall response mode at low equivalent explosive masses, transitional response mode at medium equivalent explosive masses, and local response mode at large equivalent explosive masses, respectively. Meanwhile, the honeycombs exhibit two deformation modes in the X2 direction, i.e., the expansion mode at low equivalent explosive masses and local inner concave mode at large equivalent explosive masses, respectively. Interestingly, a counter-intuitive phenomenon is observed on the loaded boundary of the H-RP. Besides, the energy distribution and buffering capacity of different parts on the honeycomb models are discussed. In a unit cell, most of the energy is absorbed by the edges with an edge thickness of $0.04 \mathrm{~mm}$ while little energy is absorbed by the other bilateral edges. For the buffering capacity, the honeycomb in the X1 direction behaves better than that in the X2 direction.
\end{abstract}

Keywords: aluminum honeycomb; deformation modes; shock wave; counter-intuitive behavior; energy distribution

\section{Introduction}

Aluminum honeycomb is a promising lightweight structure-a typical bionic structure [1-3]. Due to the homogeneous deformation mechanism [4], high strength to weight ratio [5], and large specific energy absorption [6,7], aluminum honeycombs have been frequently applied in many important engineering fields in recent years, such as aircraft, aerospace, transportation, building, and sporting equipment, which are involved in the dynamic impact or indirect explosive load. Hexagonal aluminum honeycomb, as one of the most widely used honeycombs, is orthotropic, i.e., one out-of-plane direction and two in-plane directions, respectively. Dynamic impact and indirect explosive load have been studied widely, while the compressive response of honeycomb structures subjected to direct explosive load is rarely researched. Hence, there is a pressing need to better understand the deformation behaviors of honeycombs subjected to direct explosion.

Numerical simulation is an effective way to study the deformation properties of honeycombs because it is difficult to observe the deformation modes of honeycombs experimentally. Therefore, there are some researchers who have conducted their work by numerical simulations [8-13]. For example, Ashab [8] investigated the mechanical behavior of aluminum hexagonal honeycombs subjected to dynamic indentation and compression loads only using ANSYS/LS-DYNA. Qiao [9] 
explored the in-plane uniaxial collapse response of a hierarchical honeycomb only by finite element simulations. Besides, there are some analogous deformation modes in references [8,9] to that studied in this work. Ruan et al. [10] observed three modes in one of the in-plane directions, $\mathrm{X}$ mode at low velocity, $\mathrm{V}$ mode at moderate velocity, and I mode at high velocity. Besides, $\mathrm{V}$ mode was also observed at low velocity and I mode at high velocity in the other direction. Hu et al. [11] obtained the same conclusion. Moreover, the cell-wall angle, the crushing velocity, and the honeycomb's relative density could determine the in-plane dynamic properties of hexagonal honeycomb at different cell-wall angles. Wang $[14,15]$ studied the combined effects with a dynamic inclined load. Oblique loads [16] in both in-plane and out-of-plane directions produced deformation modes from X, V, I modes to Half-X mode, Half-X following I mode, V mode, and I mode. Sun et al. [17] concluded that the impacting velocities were related to the stress when all configuration parameters were kept constant. Numerical models could adequately approximate the study of the in-plane deformation properties of honeycombs.

In engineering applications, such as explosion-proof tank, weapon protection engineering, it is possible that honeycomb is subjected to explosive loading. $\mathrm{Li}$ et al. [18] investigated the blast resistance of a square sandwich including hexagonal aluminum honeycomb cores, with different cell side lengths of the core. They concluded that failure modes of face sheets were related to the scaled distance of the explosive and the deformation modes of honeycomb core included full densified, progressive buckling, shear deformation, and fragments. Zhu et al. [19] studied the dynamic properties of a sandwich structure with a honeycomb core by air blast experiments. They thought deformation modes were mainly related to face sheet thickness and honeycomb core density. Li et al. [20] investigated the pressure distribution and the structural response of a sandwich with graded honeycomb cores. Three deformation modes were classified: large inelastic bending deformation without a significantly localized core compression, large inelastic bending deformation with significantly localized core compression, and large inelastic bending deformation with localized penetration. Jin et al. [21] proposed an innovative sandwich structure with an auxetic re-entrant cell honeycomb core and investigated its blast resistance by simulation. They showed that both the graded honeycomb cores and the cross-arranged honeycomb cores were better than the ungraded honeycomb cores and regular-arranged cores in the resistance ability. More work with different configurations or various combined structures were also studied by explosive loading [22-25]. A common feature of these studies is the indirect interaction between explosive loading and honeycomb structures.

According to the literature above, deformation properties of honeycomb under dynamic impact or indirect explosive loading have mostly been analyzed, but it is rare to study in-plane deformation characteristics of aluminum honeycomb structure core impacted by direct blast load. There are two typical applications that led to this work. One is as a passive explosive wave energy sensor, which has the characteristics of a low-cost, no electricity measurement and shock wave energy measurement under bad environment, while the other is as a shock absorber in the spaceflight separator, which can effectively reduce the shock to protect the electronic equipment on the test platform. However, deformation characteristics and energy distribution of honeycomb structures subjected to direct explosive loads are unclear.

This work focuses on the direct interaction between the honeycomb structure and spherical blast wave. The layout of the rest of the paper is arranged as follows. In Section 2, a hexagonal honeycomb structure is proposed with a cell length of $2 \mathrm{~mm}$ and $0.04 \mathrm{~mm}$ thickness with four edges and $0.08 \mathrm{~mm}$ with two edges. Besides, double finite element models in Section 3, including honeycomb-rigid plate (H-RP) and rigid plate-honeycomb-rigid plate (RP-H-RP) in the two in-plane directions with a $50 \mathrm{~cm}$ fixed explosive height, are created. Then, in Section 4, deformation modes of the models are described, and more details are given about the deformation properties and mechanism. In particular, the energy distribution of different parts and contact stress comparisons during the whole process are discussed and analyzed in Section 5, followed by a conclusion in Section 6. It is noted that the study is only a preliminary numerical example, which provides a new idea to explore the in-plane deformation regularity of honeycombs under direct explosion by numerical simulation. This work 
enables the improvement of the energy absorption and buffering capacity of honeycomb used in an explosive environment.

\section{Honeycomb Core and Loading Setup}

\subsection{Honeycomb Core}

An orthotropic hexagonal honeycomb structure (Figure 1a) is constructed by some regular hexagonal cells (Figure 1b) using the stretch forming method. Briefly, the direction along the stretch forming of the honeycomb structure is the X1 direction. The vertical direction of X1 in the in-plane is referred to as the $X 2$ direction, and $X 3$ is along the out-of-plane direction. The in-plane dimension of the aluminum honeycomb sample (X1-X2) is $47.6 \mathrm{~mm} \times 46.0 \mathrm{~mm}$ with a height of $4 \mathrm{~mm}$, based on an experimental honeycomb sample, and the number of repeated unit cells in the $X 1$ and $X 2$ directions is 14 and 15, respectively. The sketch of a unit cell is shown in Figure 1b. The edge length of the unit is $2 \mathrm{~mm}$ and the angle between each adjacent edge is $120^{\circ}$. Due to the processing method, the cell wall thickness in the X1 direction, which is $0.08 \mathrm{~mm}$, is twice that of the other directions.

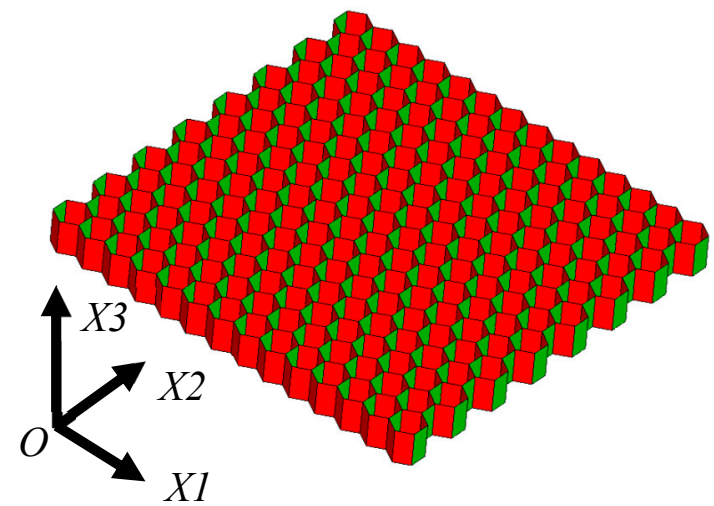

(a)

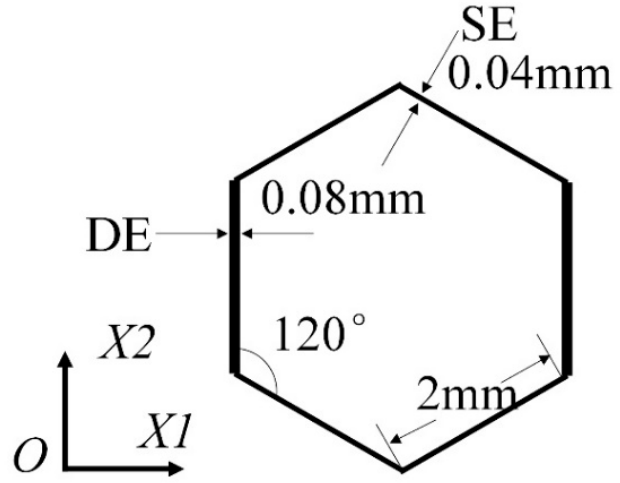

(b)

Figure 1. (a) A regular hexagonal honeycomb and (b) the sketch of a single unit cell.

\subsection{Loading Setup}

The present work creates two types of models under air blast, which are the honeycomb-rigid panel (H-RP) and the rigid panel-honeycomb-rigid (RP-H-RP), respectively, as sketched in Figure 2. The H-RP is used to analyze the mechanical and energy-absorbing properties of honeycomb structures subjected to the direct shock wave. For comparison, RP-H-RP is subjected to the indirect shock wave, where deformation of the rigid plate is ignored. In both models, the bottom rigid plate is fixed. Besides, a spherical explosive wave is realized by an air explosion. The honeycomb is loaded in both the $X 1$ direction and the $X 2$ direction, respectively, for each model. Besides, the height of the burst in this work is fixed as $50 \mathrm{~cm}$, which describes the distance between the explosive and the ceiling of the model. 


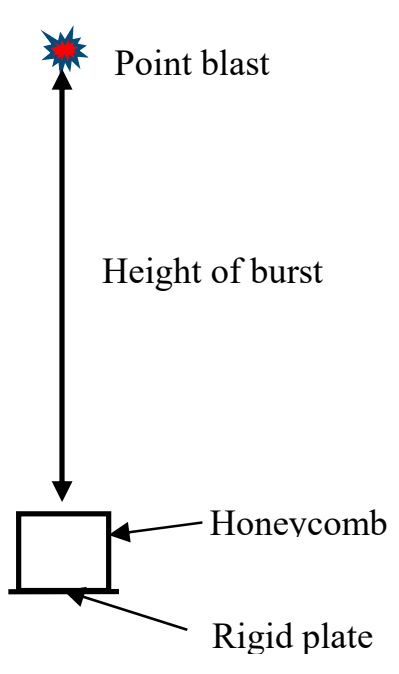

(a)

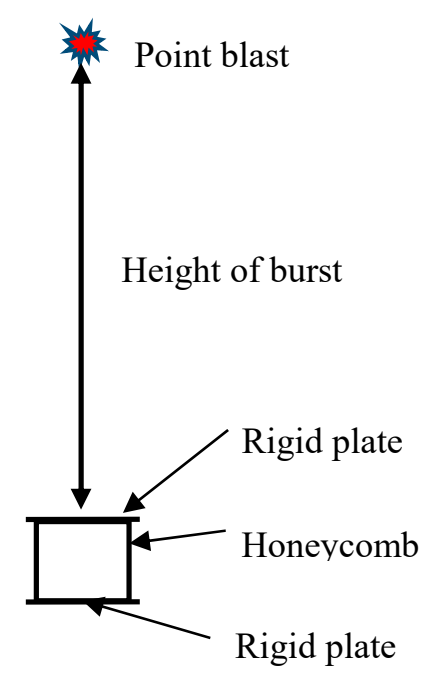

(b)

Figure 2. Two types of sketch models under air blast, (a) honeycomb-rigid plate and (b) rigid plate-honeycomb-rigid plate.

\section{Numerical Simulation}

\subsection{Finite Element Models}

Numerical simulation is conducted by ANSYS/LS-DYNA (Version 971), a popular software to simulate the dynamic impact or detonation. Based on two types of models in Section 2.2, related finite element in-plane models are created, as shown in Figure 3. Three parts are included in the H-RP (Figure 3a), in which Part 1 is the cell's double edges with $0.08 \mathrm{~mm}$ thickness (marked as DE), Part 2 is the cell's single edges with $0.04 \mathrm{~mm}$ thickness (marked as SE), and Part 3 is the bottom rigid plate which is constrained in all directions. The ceiling of the honeycomb is a loaded surface. In addition, there are four parts in the RP-H-RP (Figure 3b). In this model, the former parts are the same as those in the H-PR, while Part 4 is the ceiling rigid plate with $0.08 \mathrm{~mm}$ thickness. The plate, as the loaded surface in the RP-H-RP, is only translated in the load direction. Besides, the size of all the grids is set as $0.125 \mathrm{~mm}$ to enable steady calculation. Both models are created from the loading directions of $X 1$ and $X 2$, respectively, to research the effect of different loading surface shapes on the deformation characteristics.

$X 1$ directrion

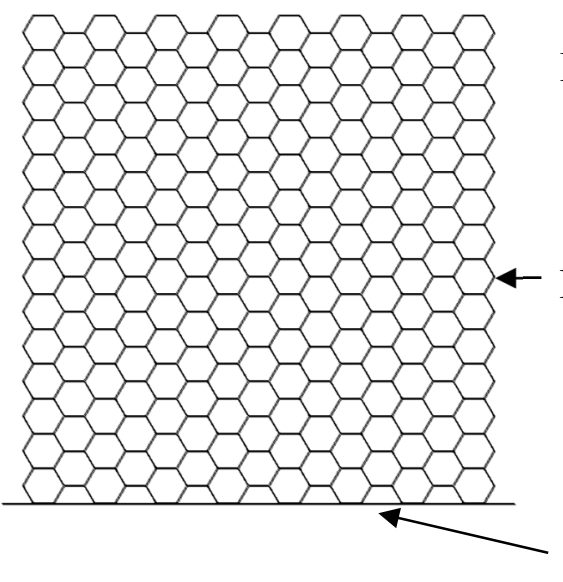

$X 2$ direction

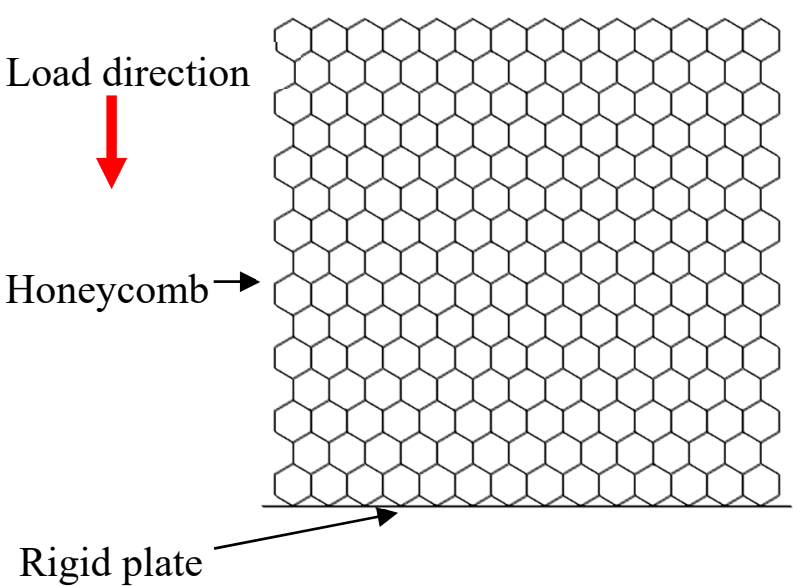

(a)

Figure 3. Cont. 


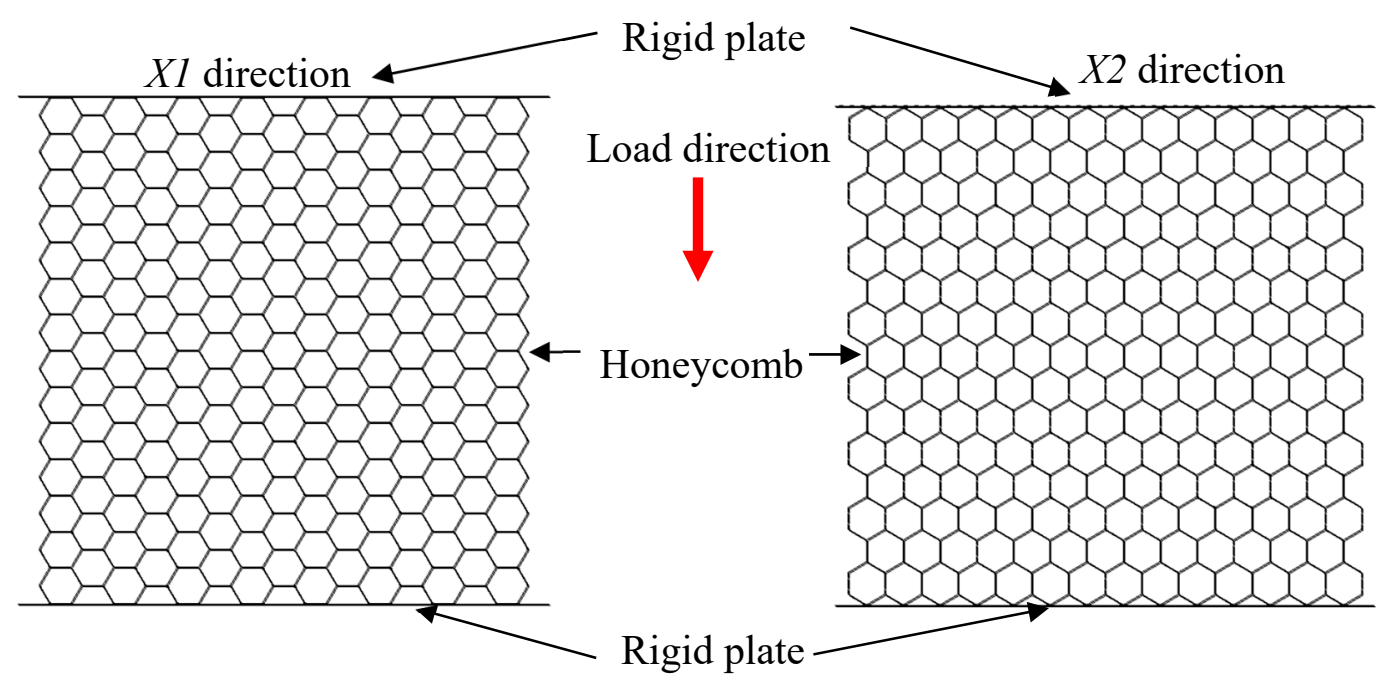

(b)

Figure 3. Equivalent finite element models, (a) honeycomb-rigid plate (H-RP) in the $X 1$ and $X 2$ direction; (b) rigid plate-honeycomb-rigid plate (RP-H-RP) in the X1 and X2 direction.

\subsection{Material Properties and Control Setup}

Here, the keyword LOAD_BLAST is used to define an air blast function for the application of pressure loads to explosives in conventional weapons, in which trinitrotoluene (TNT) is used as the explosive to simulate the detonation in the keyword file. Related parameters of TNT are taken from reference [26]. Besides, MAT_PLASTIC_KINEMATIC is a material model in the ANSYS/LS-DYNA (Version 971) software to describe the honeycomb structure of the parent material aluminum alloy 3003H18. MAT_RIGID is a rigid material to describe the rigid plate in the bottom/ceiling, where steel material parameters are used to replace parameters of the rigid body. The specific material parameters are shown in Table 1.

Table 1. Material parameters.

\begin{tabular}{ccccc}
\hline Parts & Density/(g.cm $\left.\mathbf{c m}^{-3}\right)$ & Elastic Modulus/(GPa) & Poisson Ratio & Ultimate Strength/(MPa) \\
\hline Honeycomb & 2.7 & 69 & 0.33 & 289.6 \\
Steel plate & 7.83 & 210 & 0.3 & - \\
\hline
\end{tabular}

In these models, all finite elements are quadrilateral 2D grids, where the thickness of the SE is $0.04 \mathrm{~mm}$, the thickness of the DE is $0.08 \mathrm{~mm}$, and the type of these elements is the Belytschko-Tsay Shell 163 with five through-thickness integration points to provide simulation accuracy. All nodes limit the freedom of translation in the $X 3$ direction. It is noted that additional components should be installed to prevent the out-of-plane deformation in actual applications. As for contacts, the automatic double-sided face is employed between parts of the models. Self-contact is used for the bucking contact of the same part. Hourglass energy and energy dissipation are computed and included in the energy balance to make the simulation accuracy. The scale factor for the computed time step is 0.9 and the output time step of energy and force is $5 \mu \mathrm{s}$. The shell elements between the different parts of the honeycomb structure are connected by common nodes. The main variable in the work is the equivalent mass of the TNT controlled by LOAD_BLAST. Three typical cases with equivalent explosive masses of $10 \mathrm{~g}, 20 \mathrm{~g}$, and $40 \mathrm{~g}$ are employed in the work.

In addition, the effect of different grid densities is analyzed. As a result, the elements with $0.125 \mathrm{~mm}$ are created in the following discussion. Besides, the mesh size also fits well with the numerical simulation results in reference [8]. However, if the mesh is further refined, it will have less and less 
influence on the deformation result, but it will take more time to calculate the model. Therefore, it could not only guarantee the efficiency of calculation but also make simulation results consistent.

In order to analyze the effect of grid density, three sizes of grids are selected, $0.5 \mathrm{~mm}, 0.25 \mathrm{~mm}$, and $0.125 \mathrm{~mm}$, respectively. Taking the $10 \mathrm{~g}$ TNT explosive as an example, the deformation characteristics of the different mesh sizes at four typical moments are obtained, as shown in Figure 4 . At the moment of $1700 \mu \mathrm{s}$, the difference in both the overall deformation and the local deformation is obvious. Concretely, the overall deformation increased from 0.26 to 0.32 with the size of the elements from $0.5 \mathrm{~mm}$ to $0.125 \mathrm{~mm}$. Besides, the concentrated deformation zone in the local position was more prominent in the model with a mesh size of $0.125 \mathrm{~mm}$. It should be noted that the compressive deformation strain is the ratio of the displacement of the upper panel to the length of the honeycomb compression direction, marked as a symbol, $\varepsilon$.

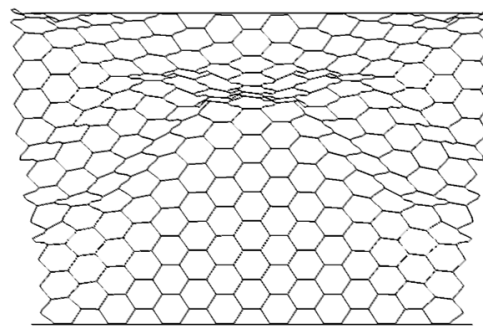

Time $=1700 \mu \mathrm{s}(\varepsilon=0.26)$

(a)

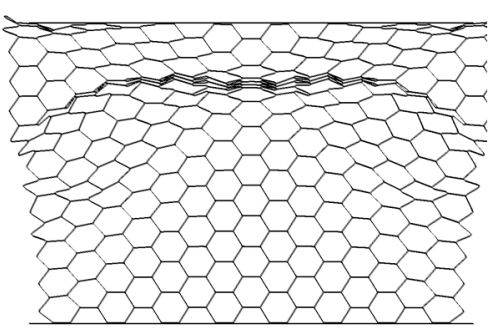

Time $=1700 \mu \mathrm{s}(\varepsilon=0.32)$

(b)

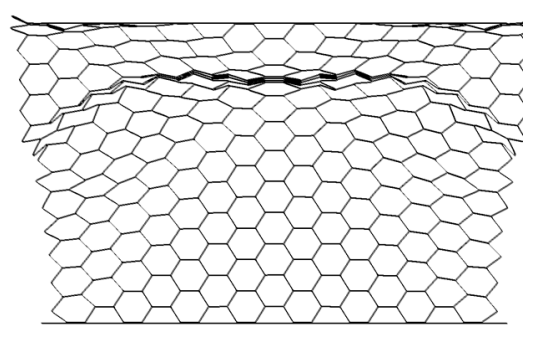

Time $=1700 \mu \mathrm{s}(\varepsilon=0.32)$

(c)

Figure 4. The deformation characteristics of three sizes of grids, (a) mesh size $=0.5 \mathrm{~mm},(\mathbf{b})$ mesh size $=0.25 \mathrm{~mm}$, and $(\mathbf{c})$ mesh size $=0.125 \mathrm{~mm}$.

\section{Deformation Modes}

\subsection{The X1-RP-H-RP}

With the increase of equivalent explosive masses (10 g, $20 \mathrm{~g}$, and $40 \mathrm{~g})$, there are three deformation modes in the $X 1$ direction, the overall response mode in the small equivalent explosive masses case, the transitional response mode in the medium equivalent explosive masses case, and the local response mode in the large equivalent explosive masses case, respectively, as shown in Figure 5. In this figure, the upper figures describe the deformation of the whole honeycomb structure, and the bottom figures record the deformation of the SE in order to observe the deformation characteristics clearly. In the bottom figures, the red lines are used to describe the shape of the local deformation belt. Besides, the subsequent description of the deformation characteristics is also presented in this way. The specific meanings of the three deformation modes are as follows, in which the deformation diagrams on display are selected based on whether the local deformation is clearly visible.

The overall response mode means all parts in the model take part in the process of deformation. In the deformation mode, the honeycomb sample is compressed by the upper panel, but the compact state of the honeycomb is not achieved. In detail, at $550 \mu \mathrm{s}$, the shock wave begins to propagate into the honeycomb structure. At the moment of $1000 \mu \mathrm{s}$, the compressive strain of the honeycomb structure

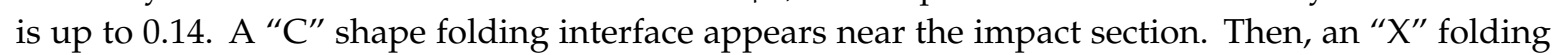
interface (or double " $\mathrm{C}$ " folding interface back to back) occurs near the upper plate at $1360 \mu \mathrm{s}$ and a " $\mathrm{C}$ " interface appears near the bottom plate. At the moment, the honeycomb structure is compressed to the maximum deformation which is 0.18 . After that, the upper panel starts to rebound with a constant speed of $5 \mathrm{~m} / \mathrm{s}$ at $1800 \mu \mathrm{s}$ because of the elastic potential energy stored in the honeycomb structure and the compression strain decreases to 0.15 . Besides, an interesting phenomenon occurs that some cells near the central axis keep the regular hexagonal configuration in the whole process, and it seems that the cells never received any load. 


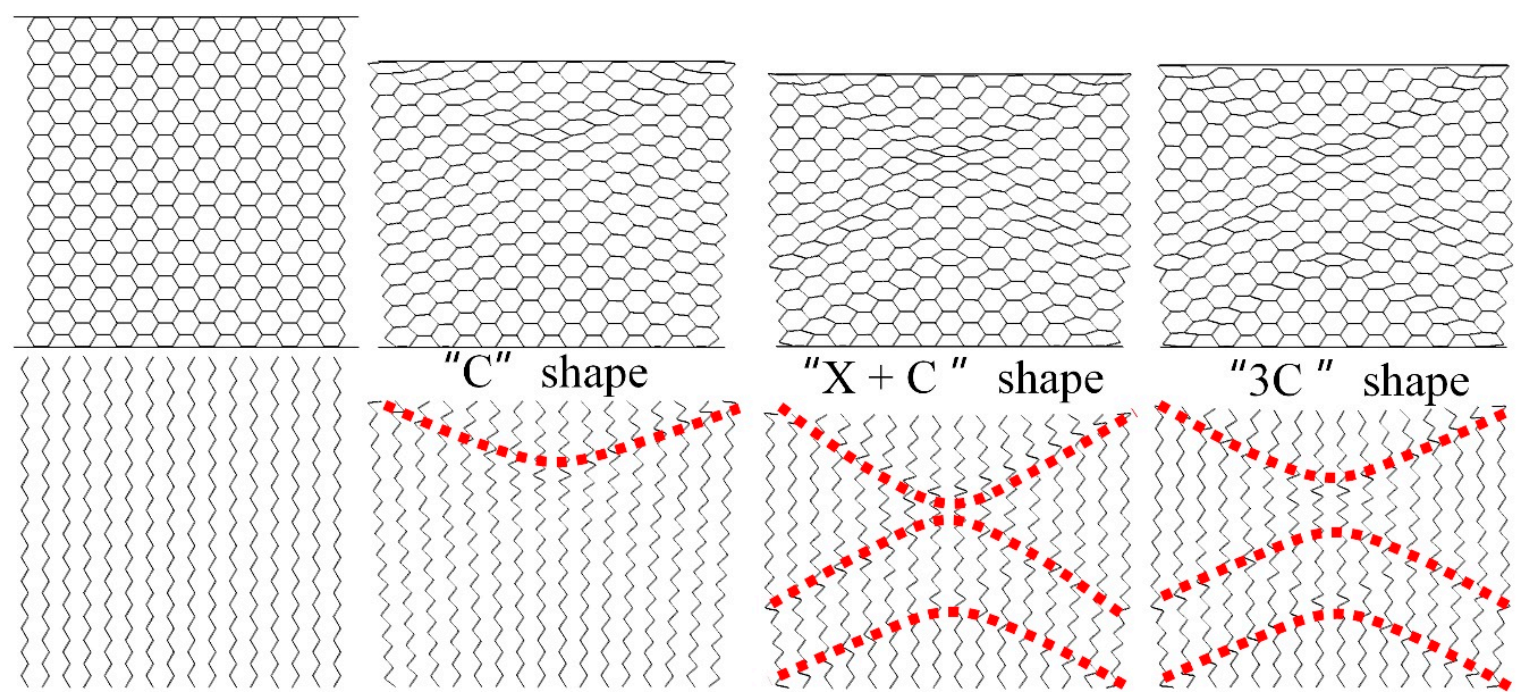

(a)

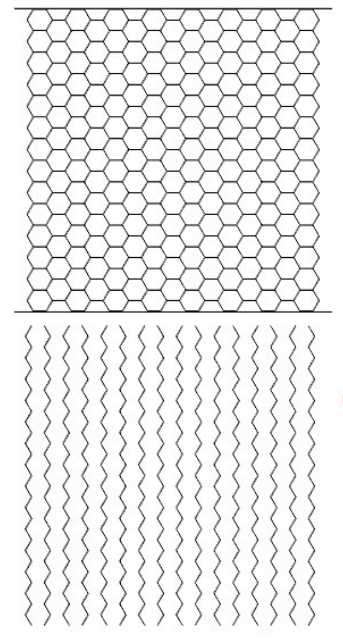

Time $=455 \mu \mathrm{s}(\varepsilon=$
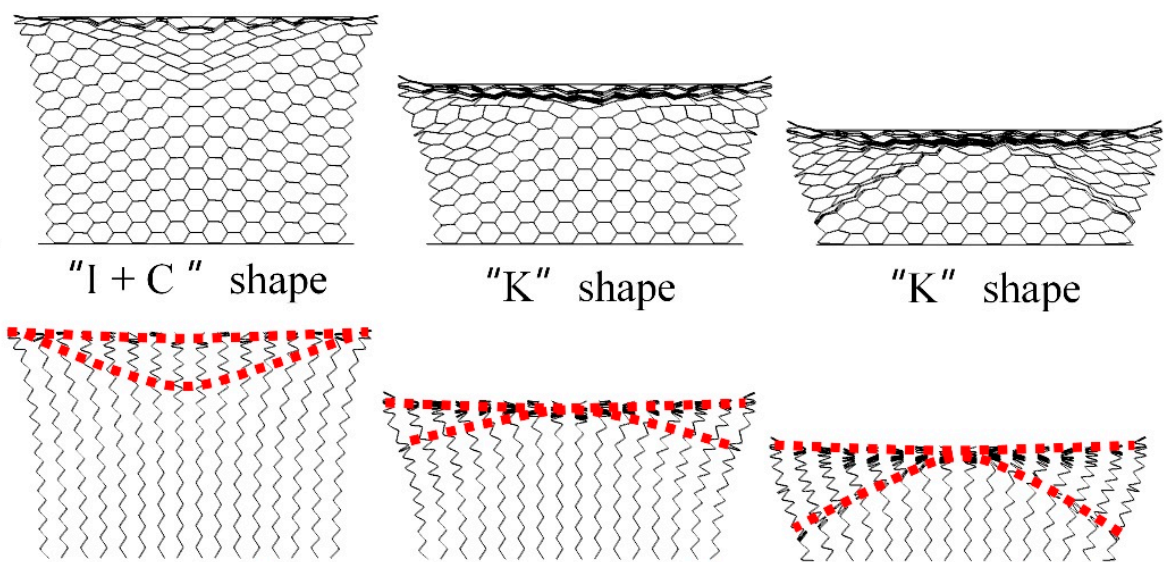

" $K$ " shape

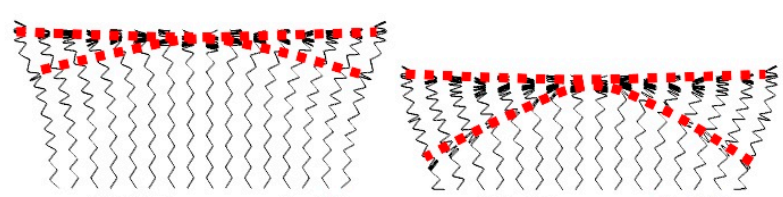

0) Time $=800 \mu \mathrm{s}(\varepsilon=0.25)$ Time $=1200 \mu \mathrm{s}(\varepsilon=0.47)$ Time $=2160 \mu \mathrm{s}(\varepsilon=0.62)$

(b)
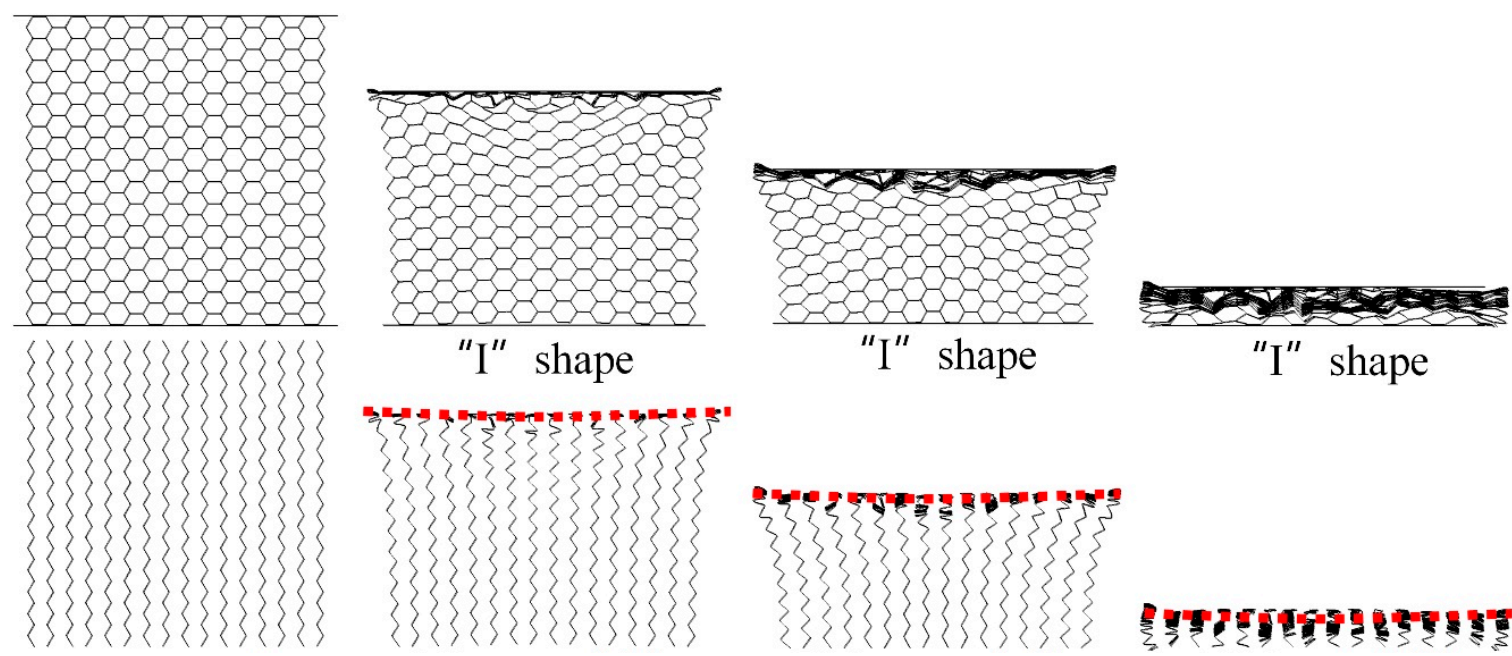

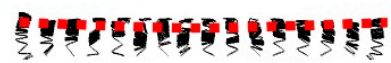

Time $=375 \mu \mathrm{s}(\varepsilon=0)$ Time $=570 \mu \mathrm{s}(\varepsilon=0.25)$ Time $=795 \mu \mathrm{s}(\varepsilon=0.50)$ Time $=1400 \mu \mathrm{s}(\varepsilon=0.88)$

(c)

Figure 5. Deformation characteristics in the X1-RP-H-RP. (a) Overall response mode, (b) Transitional response mode, and (c) Local response mode. 
In the transitional response mode, the honeycomb sample can be exactly compact. The blast wave reaches the honeycomb structure at $455 \mu \mathrm{s}$. At $800 \mu \mathrm{s}$, the compression strain of the whole honeycomb structure is 0.25 , which has exceeded the maximum deformation in the overall response mode. At this moment, the clear deformation interface in the honeycomb structure is a mixed buckling region of "I" and " $\mathrm{C}$ " shape, while the area near the upper panel shows the local compaction state and presents the "I" shape. Then, the shape of " $\mathrm{C}$ " becomes plain gradually and becomes the " $\mathrm{K}$ " mode at the moment of $1200 \mu \mathrm{s}$. Once the folding degree of the cells close to the upper panel at the end of the impact section increased to 0.62 at $1800 \mu \mathrm{s}$, a larger span of "K" shape occurs. At last, the upper panel bounces back at $6.7 \mathrm{~m} / \mathrm{s}$. In addition, the "regular cells" mentioned in the overall response mode disappear in the transitional response mode.

The local response mode is similar to the high-speed loading of deformation proposed by $\mathrm{Hu}$ [8]. At $375 \mu \mathrm{s}$, the honeycomb structure begins to be loaded by a shock wave. On the upper panel, a local " $\mathrm{I}$ " shape interface appears in the honeycomb structure at $570 \mu \mathrm{s}$, while honeycomb cells near the bottom rigid plate are not deformed and then at $795 \mu \mathrm{s}$, the " $\mathrm{I}$ " shape interface is clearer. The maximum compression strain is 0.88 at $1400 \mu$ s. The sample reaches the compact state in the mode. The upper panel rebounds back eventually at $7.4 \mathrm{~m} / \mathrm{s}$.

\subsection{The $X 2-R P-H-R P$}

The $X 2$ direction is perpendicular to the $X 1$ direction in the in-plane region. In order to compare the deformation difference with the X1-RP-H-RP, the explosion load is also applied in the X2-RP-H-RP. Two types of deformation modes occur, expansion mode in the small equivalent explosive masses case and local inner concave mode in the large equivalent explosive masses case, respectively, as illustrated in Figure 6.

Taking the $10 \mathrm{~g}$ TNT as an example of the small equivalent mass cases, the honeycomb sample is expanded across the whole compression process in the expansion mode, but it fails to reach the compact state. In this model, the time for the explosive wave to reach the loading surface is the same as that in X1-RP-H-RP, both of which are $550 \mu \mathrm{s}$, because they have the same explosive yield and blast height. At $890 \mu \mathrm{s}(\varepsilon=0.14)$, there is an obvious lateral expansion by the way of stretching transversely of the SE. The mechanism makes the cell shape change from the convex hexagon to the square or even concave hexagon. At the moment of $1260 \mu$ s, the deformation reaches the maximum, i.e., $\varepsilon=0.18$. The impacted region forms " $\nabla$ " shape area, a series of " $\mathrm{I}$ " interfaces. At last, the overall elasticity properties make the ceiling plate rebound with $5.7 \mathrm{~m} / \mathrm{s}$. The case of $20 \mathrm{~g}$ is similar to the case of $10 \mathrm{~g}$. Local inner concave mode occurs at large equivalent explosive masses (for example, $40 \mathrm{~g}$ TNT in Figure $6 \mathrm{~b}$ ). The explosion shock wave begins to propagate in the honeycomb sample at $375 \mu \mathrm{s}$. At the moment of $560 \mu \mathrm{s}$, the strain of the honeycomb sample is compressed to be 0.25 . An "I" interface appears near the impact region. Then, a "bow" shape forms at $790 \mu \mathrm{s}(\varepsilon=0.50)$ and an "M" interface becomes contour of honeycomb structure at $1570 \mu \mathrm{s}(\varepsilon=0.88)$. 

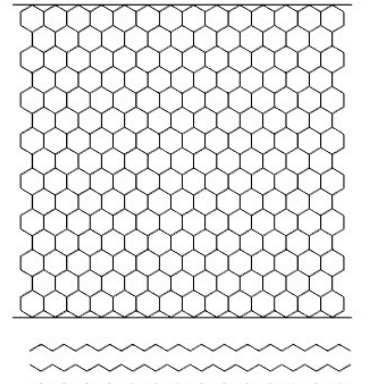
(n) (n)

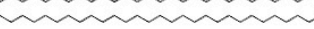
(n) (n) (n) (n) (1) (n)

Time $=550 \mu \mathrm{s}(\varepsilon=0)$ Time $=890 \mu \mathrm{s}(\varepsilon=0.14)$ Tin
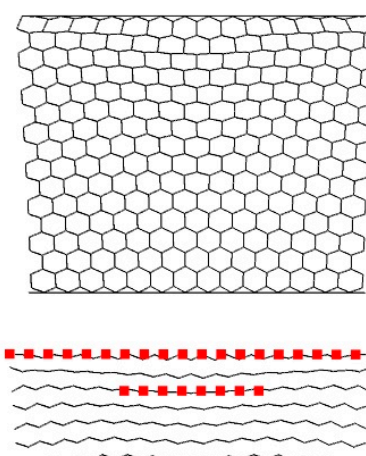

no
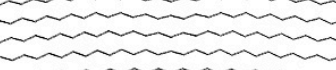

(n) (n) (1)

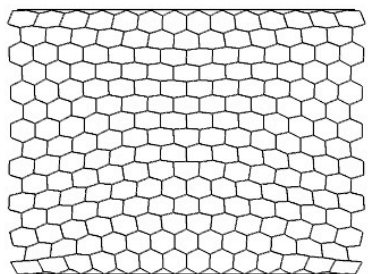

$" \nabla$ " shape

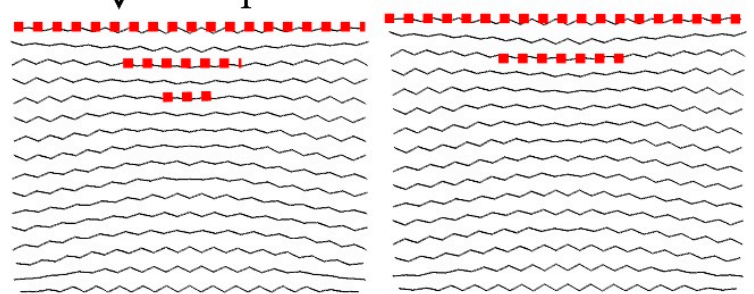

me $=1260 \mu \mathrm{s}(\varepsilon=0.18)$ Time $=1700 \mu \mathrm{s}(\varepsilon=0.15)$

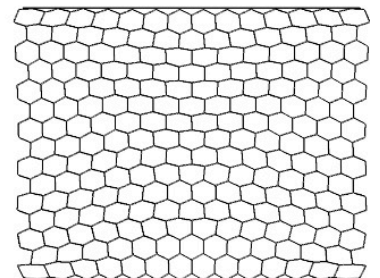

(a)

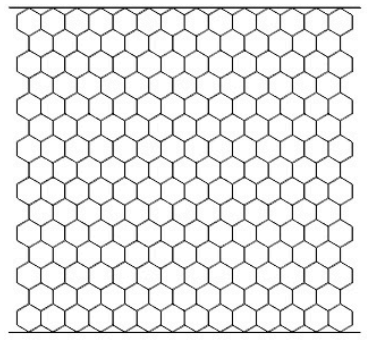

minch m (n) (n) m mon  m man man (1)

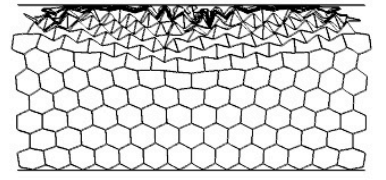
"I" shape

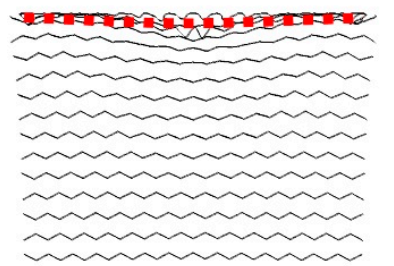

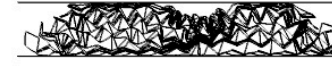

"M" shape

Time $=375 \mu \mathrm{s}(\varepsilon=0)$ Time $=560 \mu \mathrm{s}(\varepsilon=0.25)$ Time $=790 \mu \mathrm{s}(\varepsilon=0.50)$ Time $=1570 \mu \mathrm{s}(\varepsilon=0.88)$

(b)

Figure 6. Deformation modes in the X2-RP-H-RP, (a) Expansion mode and (b) Local inner concave mode.

\section{3. $H-R P$}

In-plane deformation characteristics of the honeycomb sandwich structures (rigid plate-honeycomb-rigid plate) are obtained with the above two models. In order to obtain the effect of the direct explosive load on the honeycomb and analyze the influence of the shape of the explosive load surface on the deformation characteristics of honeycomb, H-RP is studied in this work. Taking $10 \mathrm{~g}$ X1-H-RP and $10 \mathrm{~g}$ X2-H-RP as examples, as illustrated in Figure 7, the same moments are used to compare with the previous two models. Similarity and unique deformation characteristics in the H-RP are shown as follows.

The similarity is shown in the internal deformation characteristics of the honeycomb structure. In X1-H-RP in Figure 7a, a "C" shape folding interface occurs near the impact section as well at $1000 \mu \mathrm{s}$. The " $C$ " interface and the upper interface form a lip-shaped interface. Then, an " $X$ " interface also occurs near the impacted section and a " $\mathrm{C}$ " interface also occurs at the opposite from the blast at $1360 \mu \mathrm{s}$. At $1800 \mu \mathrm{s}$, the honeycomb structure is also rebounded because of the elastic properties. In the X2-H-RP in Figure 7b, the honeycomb sample is also expanded, but the honeycomb structure is not compacted. This expansion changes the shape of the cellular structure of the honeycomb from a convex hexagon 
to a quadrilateral as well at $890 \mu \mathrm{s}$. At $1260 \mu \mathrm{s}$, the impacted region also forms a " $\nabla$ " shape area, consisting of a series of horizontal lines. Besides, the deformation similarity is also verified in the cases of medium (20 g) and large explosives (40 g).

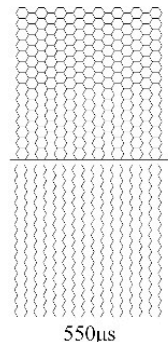

$550 \mu \mathrm{s}$

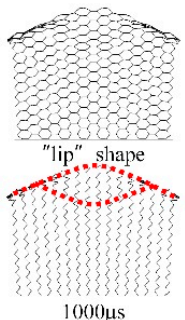

$1000 \mathrm{us}$

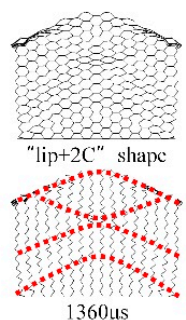

(a)

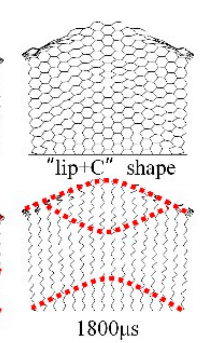

$1800 \mu \mathrm{s}$

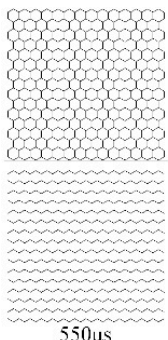

$550 \mathrm{us}$
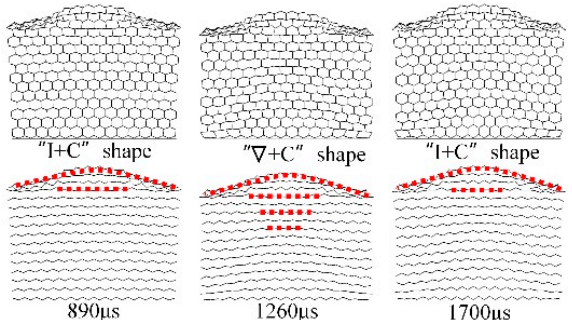

(b)

Figure 7. Deformation modes in the H-RP. (a) $10 \mathrm{~g}$ X1-H-RP and (b) $10 \mathrm{~g}$ X2-H-RP.

Different from the deformation characteristics of the RP-H-RP, a counter-intuitive deformation phenomenon appears near the explosive load surface in the H-RP. In this phenomenon, the shape of the loading wave is a concave face while the deformation surface of the honeycomb structure is a convex face in in-plane directions, as shown in Figure 7. It's worth mentioning that the counter-intuitive phenomenon always exists, with the increase of equivalent explosive masses.

\subsection{Discussion on Deformation Mechanism}

Due to the low density of the honeycomb structure, the variation of the honeycomb structure deformation characteristics is essentially caused by the influence of the upper and lower panels on the propagation of the blast wave in these models.

The propagation process of the shock wave in the honeycomb structure is shown in Figure 8a for RP-H-PR and Figure $8 \mathrm{~b}$ for H-RP. In Figure 8, the shock wave just reaches the upper interface of the honeycomb at the moment T1. The wave is a concave interface. Then, the shock wave is reflected at the moment T2, whose shape is a convex interface because of the fixed bottom panel. T3 represents the moment when the reflected shock wave reaches the upper interface and reflects again. For the RP-H-RP with an upper panel, the concave shock wave is reflected again because of the reflection of the upper rigid panel. However, for the H-RP without the upper panel, the reflected wave is a concave sparse wave due to the upper interface, which is a free surface. Therefore, the " $\mathrm{C}^{\text {" }}$-shaped interface in the honeycomb is actually the propagation of the interface of the shock wave in the honeycomb structure. The shape of the ceiling surface of the honeycomb structure is the same as that of the convex shock wave, rather than the concave one. This is the reason for the counter-intuitive deformation phenomenon. 


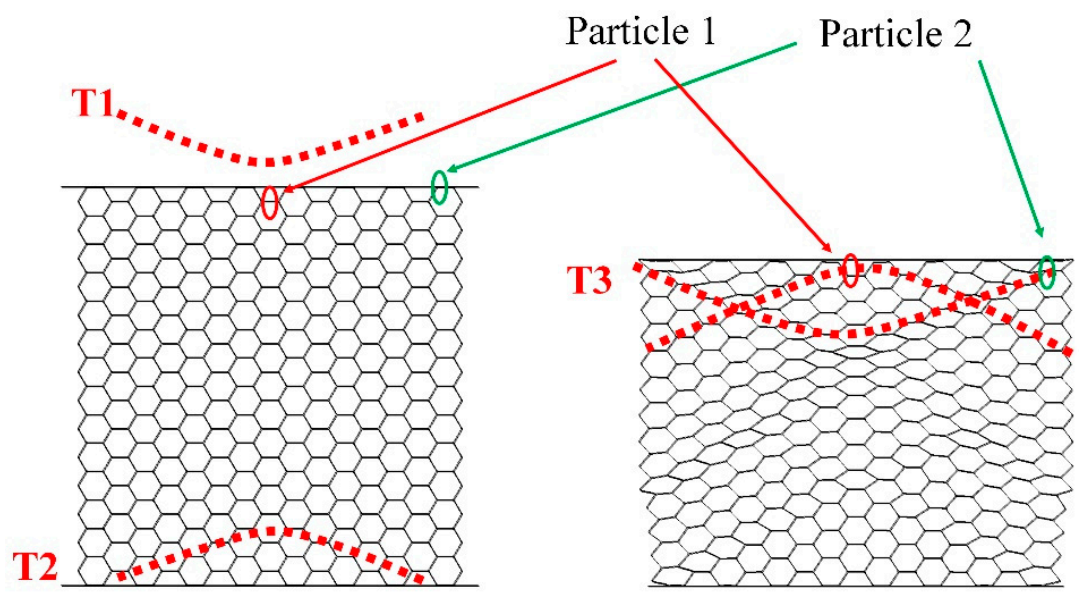

(a)

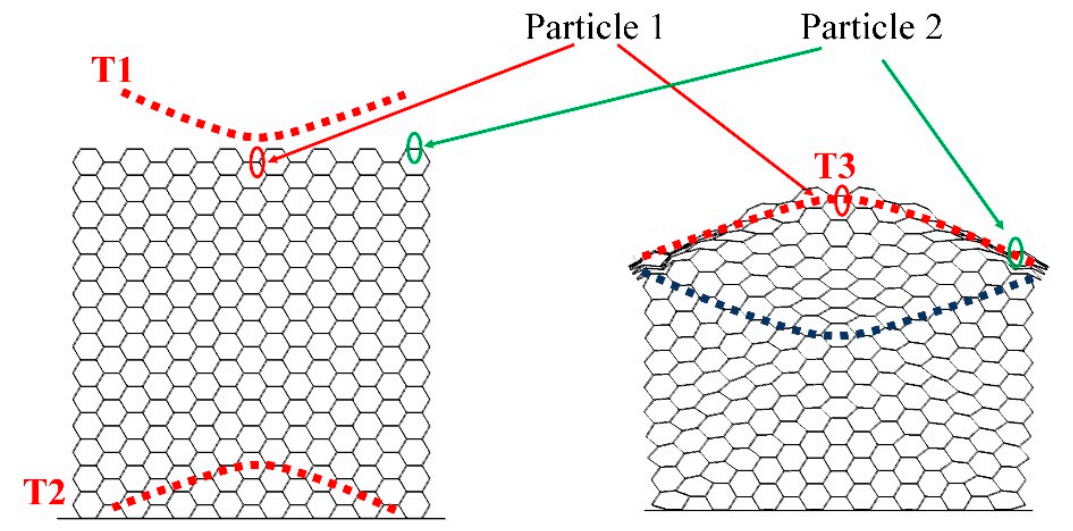

(b)

Figure 8. Wave propagation at different moments. (a) RP-H-RP and (b) H-RP.

Two typical locations are selected from the honeycomb to analyze the honeycomb deformation distribution. Particle 1 is a particle in the middle of the upper interface of the honeycomb, indicated by a red circle. Particle 2 is a particle in the right area of the interface on the honeycomb, represented by a green circle, as shown in Figure 8. At the moment T3, the motion state of the two particles is shown in Figure 9. The particle velocity is the same as the wave direction in the shock wave, while the particle velocity is opposite in the sparse wave. In Figure 9, $v 1$ is the velocity after the action of the upward convex shock wave, $v 2$ is the velocity after the action of the reflected wave at the upper interface, and $v 0$ is the velocity of the upper panel. The directions of these speeds is shown in Figure 9. For RP-H-RP in Figure $9 \mathrm{a}$, the direction of $v 1$ and $v 2$ is opposite, so both particle 1 and particle 2 have moved downward at the velocity of $v 0$, which is consistent with the deformation state in Figure 8. However, For H-RP in Figure $9 \mathrm{~b}$, the $v 1$ and $v 2$ are moving in the same direction, so Particle 1 is moving up at $(v 1+v 2)$, and Particle 2 is moving up at $v 4$, which is the vertical component of $(v 1+v 2)$. Therefore, Particle 1 is above particle 2 because $v 4$ is less than $(v 1+v 2)$. In addition, $v 3$, the horizontal component of $(v 1+v 2)$, causes Particle 2 to shift in the horizontal direction, so the upper interface will expand to both sides. 


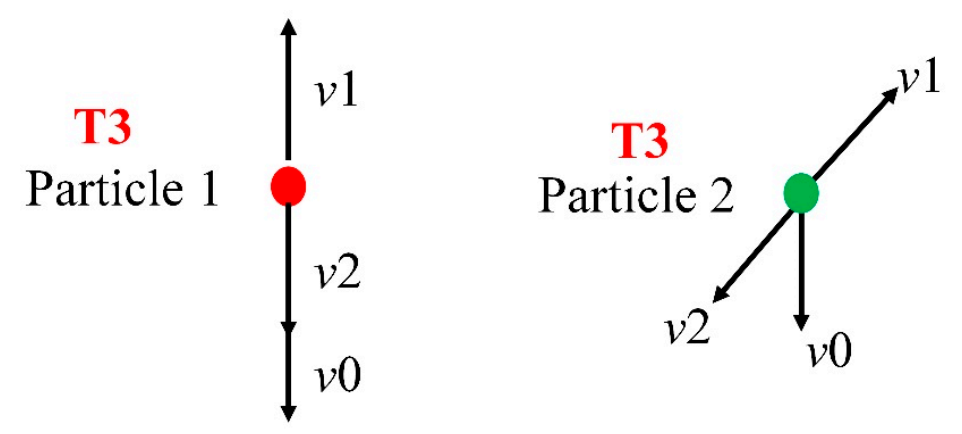

(a)
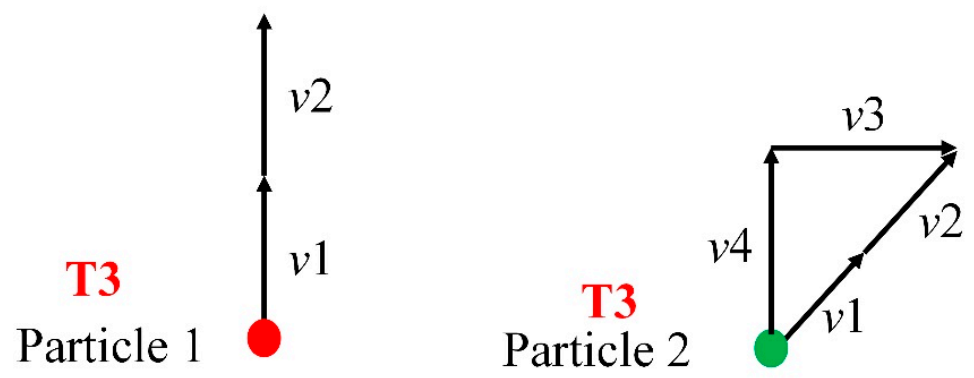

(b)

Figure 9. Schematic diagram of particles' motion at the moment T3, (a) the particles near the top with a rigid plate and $(\mathbf{b})$ the particles near the top without a rigid plate.

\section{Analysis of Energy and Stress Properties}

\subsection{Energy Distribution}

For RP-H-RP, the total energy is divided into five parts at different moments, internal energy of SE, internal energy of DE, kinetic energy of rigid plate (marked as RP), kinetic energy of SE, and kinetic energy of $\mathrm{DE}$, respectively. In order to compare the energy distribution of each part during the compression process, the energy ratio $\zeta$ is defined as follows,

$$
\zeta=\frac{E_{\text {part }}}{E_{\text {total }}} \times 100 \%
$$

where $E_{\mathrm{part}}$ represents one or more of the five components mentioned above, $E_{\text {total }}$ is the total energy of the model.

Once the shock wave reaches the rigid plate in X1-RP-H-RP (Figure 10) or X2-RP-H-RP (Figure 11), most of the energy is converted immediately to the kinetic energy of the rigid plate $(76.5 \%$ in overall response mode, $77.5 \%$ in transitional response mode, $59 \%$ in local response mode, $87.5 \%$ in expansion mode, and $62.0 \%$ in the local inner concave mode), and a little becomes the internal energy of honeycomb structure. Then, a partition of the kinetic energy of RP and the elastic energy of the honeycomb are transferred into the kinetic energy of the honeycomb. Before bouncing back of the rigid plate, the kinetic energy of all the parts decreases. However, the internal energy of the SE increases greatly and the internal energy of the DE increases slightly. With the increase of the explosive yield, the effect becomes more obvious. In addition, the kinetic energy of the SE and DE remains basically the same in the process. 


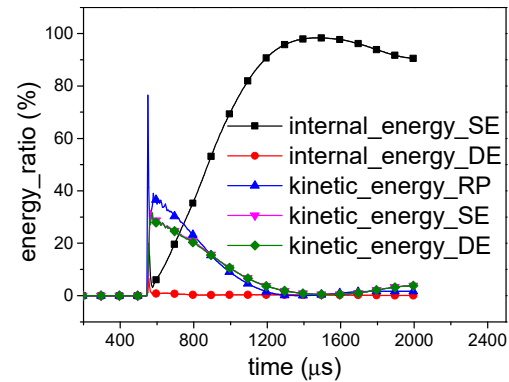

(a)

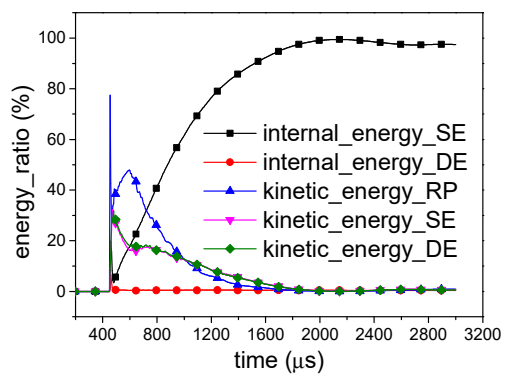

(b)

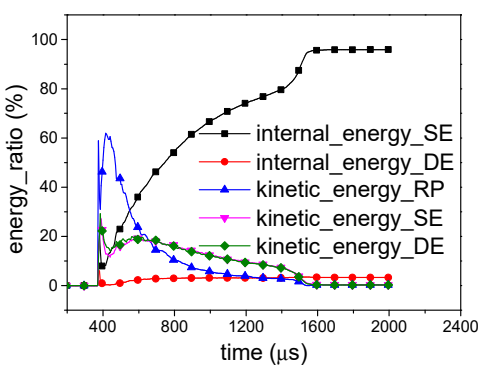

(c)

Figure 10. Energy distribution in X1-RP-H-RP. (a) Overall response mode; (b) Transitional response mode; (c) Local response mode.

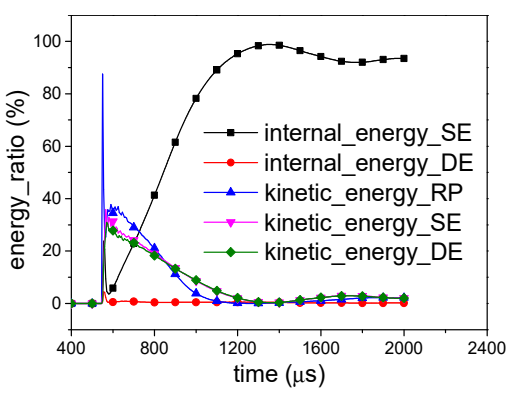

(a)

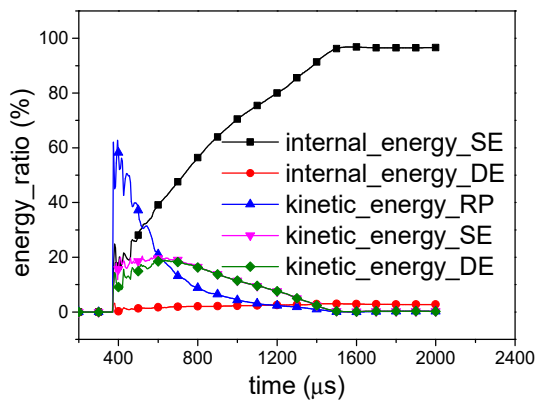

(b)

Figure 11. Energy distribution in X2-RP-H-RP. (a) Expansion mode and (b) Local inner concave mode.

According to Figures 10 and 11, the deformation mode of the honeycomb can be judged from the kinetic energy and internal energy of DE. If the kinetic energy of DE is less than the internal energy of $\mathrm{DE}$, the deformation mode of the honeycomb presents as an overall response or expansion mode. Otherwise, the deformation mode of the honeycomb is the local response mode.

For the H-RP, the total energy is divided into four parts, the kinetic energy and internal energy of SE and the kinetic energy and internal energy of DE, respectively, as illustrated in Figure 12. Once the shock wave reaches the ceiling of the honeycomb, $79.6 \%$ of the total energy is distributed to the kinetic energy of the DE for $\mathrm{X} 1-\mathrm{H}-\mathrm{RP}$ and $76.3 \%$ of the total energy is distributed to kinetic energy of SE for X2-H-RP. In the subsequent process, the kinetic energies of SE and DE are basically equal. Finally, the total energy is converted to internal energy of SE.

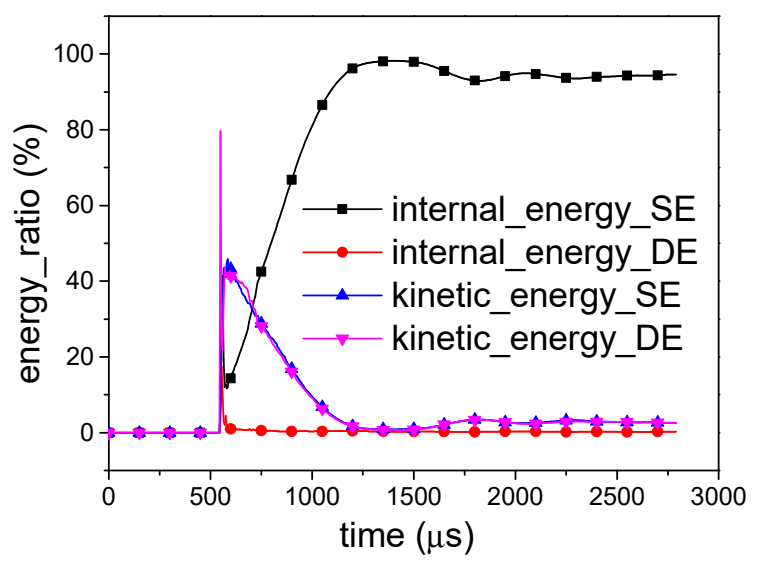

(a)

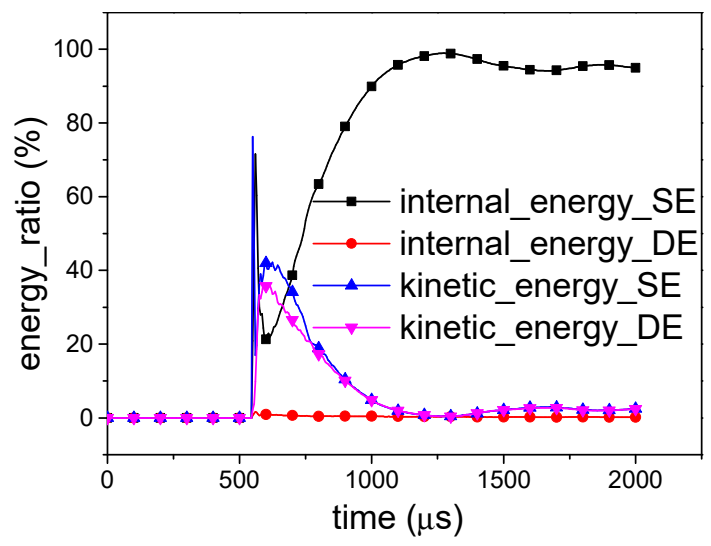

(b)

Figure 12. Energy distribution of H-RP. (a) X1-H-RP-10g and (b) X2-H-RP-10g. 
It is noted that SE produces plastic deformation and converts total energy into deformation energy, while DE merely transfers energy in the form of kinetic energy. Therefore, in order to improve the energy absorption effect of a honeycomb structure, DE can be involved in the plastic deformation process through the optimization design. This provides a good way to enhance energy absorption.

Although the RP-H-RP and H-RP differ only by the ceiling rigid plate, the plate has an obvious effect on the energy absorption of the honeycomb structure. The internal energy of the SE in the -RP and RP-H-RP is compared in Figure 13. Once the shock wave reaches, $41.4 \%$ is absorbed for H-RP while $19.9 \%$ for RP-H-RP in the X1 direction and $71.6 \%$ is absorbed for H-RP while $23.8 \%$ for RP-H-RP in the X2 direction, respectively. Besides, the H-RP has more proportion of the energy, including elastic energy and plastic deformation energy of SE. However, the plate does not affect the energy absorption rate of the honeycomb structure.

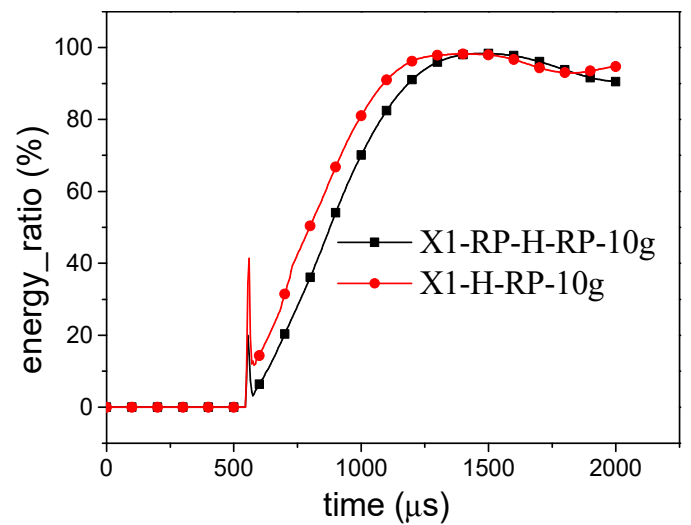

(a)

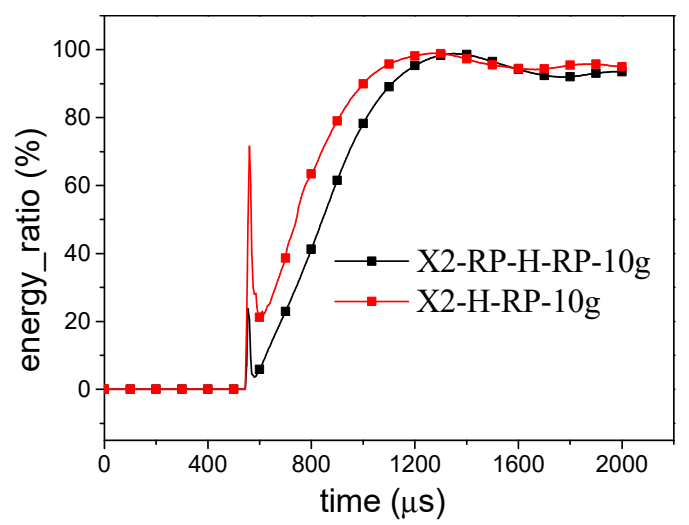

(b)

Figure 13. Comparison of energy distribution between RP-H-RP-10g and H-RP-10g (a) in the X1 direction and $(\mathbf{b})$ in the $\mathrm{X} 2$ direction.

\subsection{Stress Analysis}

For a buffering material, the peak stress is an important parameter to access the buffering ability of honeycombs. In order to describe the stress attenuation effect of the honeycomb structure, the buffering coefficient $\eta$ is defined as follows,

$$
\eta=\frac{\sigma_{\mathrm{cp}}-\sigma_{\mathrm{bp}}}{\sigma_{\mathrm{cp}}} \times 100 \%
$$

where $\sigma_{\mathrm{cp}}$ is the initial contact peak stress between the honeycomb and the ceiling rigid plate and $\sigma_{\mathrm{bp}}$ is the initial contact peak force between honeycomb and the bottom rigid plate. The large buffering coefficient is beneficial to the structure buffering effect.

For $10 \mathrm{~g}$ RP-H-RP, as shown in Figures 14a and 15a, the ceiling rigid plate gets the initial peak stress and about $15 \mu$ s later, the peak stress occurs in the bottom rigid plate, but its amplitude is decreased. Then, the stress in the ceiling rigid plate decreases rapidly and the stress in the bottom rigid plate increases. They are equal at about $800 \mu \mathrm{s}$. In the next stage, the stress response of the bottom plate is a platform. It is larger than the stress in the ceiling plate. It has a similar characteristic for $20 \mathrm{~g}$ RP-H-RP, as shown in Figure 14b. However, the bottom plate has a longer platform stress response. The stress in the bottom rigid plate increases rapidly at the final state for $40 \mathrm{~g} \mathrm{RP}-\mathrm{H}-\mathrm{RP}$ in Figures 14c and 15b. At this moment, the honeycomb specimen has been crushed. Besides, in different deformation modes, $\eta$ is calculated as shown in Table 2 . It can be seen that $\eta$ is not correlated with the equivalent explosive masses, which is $73.06 \%$ in the $X 1$ direction and $65.72 \%$ in the $X 2$ direction, though a small rise with the masses. Therefore, the buffering effect in the $\mathrm{X} 1$ direction is better than that in the $\mathrm{X} 2$ direction. 


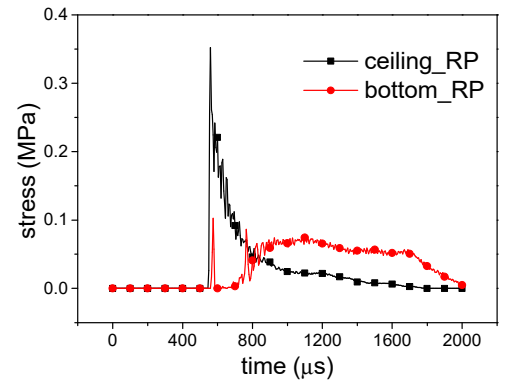

(a)

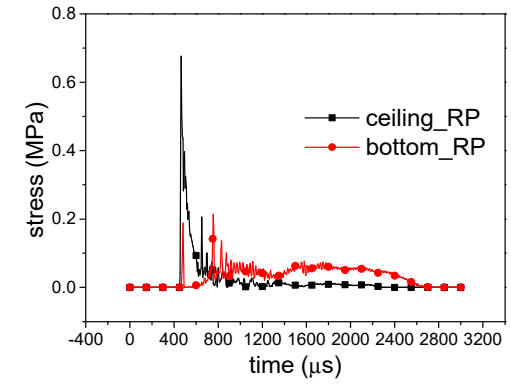

(b)

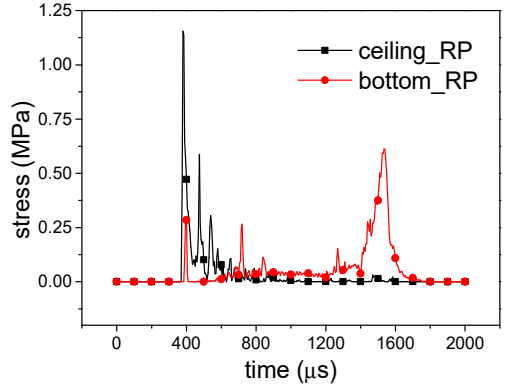

(c)

Figure 14. Stress-time curves of X1-RP-H-RP; (a) Overall response mode; (b) Transitional response mode and (c) Local response mode.

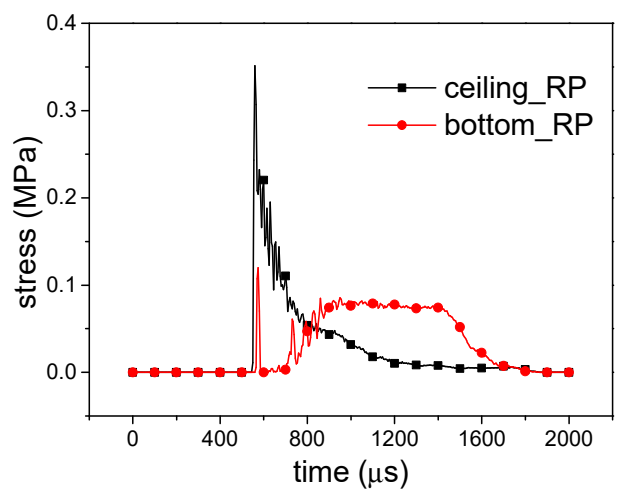

(a)

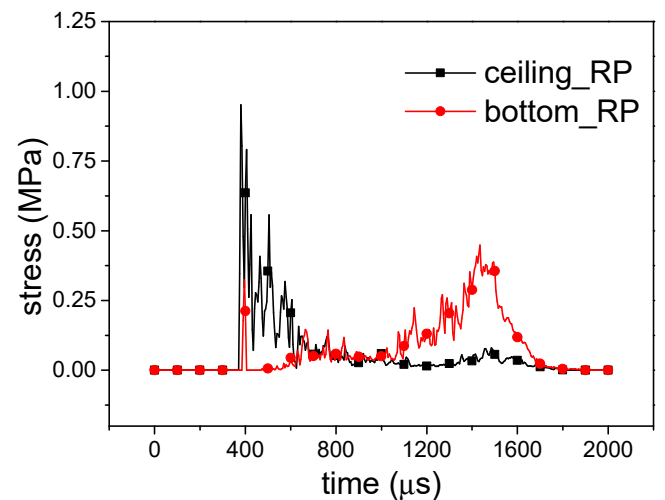

(b)

Figure 15. Stress-time curves of X2-RP-H-RP. (a) Expansion mode and (b) Local inner concave mode.

Table 2. The buffering effect under different equivalent explosive masses.

\begin{tabular}{ccccc}
\hline Cases & Deformation Modes & $\sigma_{c p} / \mathbf{M P a}$ & $\sigma_{b p} / \mathbf{M P a}$ & $\eta / \%$ \\
\hline 10 g X1-RP-H-RP & Overall & 0.35 & 0.10 & 70.86 \\
20 g X1-RP-H-RP & Transitional & 0.68 & 0.19 & 72.24 \\
40 g X1-RP-H-RP & Local & 1.16 & 0.28 & 76.07 \\
Average & & - & - & 73.06 \\
\hline 10 g X2-RP-H-RP & Expansion & 0.35 & 0.12 & 65.79 \\
40 g X2-RP-H-RP & Local inner concave & 0.95 & 0.32 & 66.08 \\
Average & & - & - & 65.72 \\
\hline
\end{tabular}

\section{Conclusions}

Lightweight aluminum honeycomb is a nice bionic material to absorb energy under explosion. Two finite element models of honeycombs whose parent material is lightweight aluminum alloy $3003 \mathrm{H} 18$, including rigid plate-honeycomb-rigid plate (RP-H-RP) and honeycomb-rigid plate (H-RP) are created to investigate the in-plane deformation properties of honeycombs subjected to air blast. Conclusions can be drawn as follows,

(1) At the different equivalent explosive masses, there are three deformation modes in the X1 direction, i.e., the overall response mode in the small equivalent explosive masses case in which there is a " $\mathrm{C}$ " or multi " $\mathrm{C}$ " folding shape, transitional response mode in the middle equivalent explosive masses case, in which there is an " $\mathrm{I}$ " and " $\mathrm{C}$ " folding shape, and the local response mode in the large equivalent explosive masses case in which there is only an " $\mathrm{I}$ " folding interface. There are mainly two deformation modes in the X2 direction, expansion mode and local inner concave mode. In the expansion mode, the shape of the convex cells is changed into concave and some " $\mathrm{I}$ " shape folding interfaces form " $\nabla$ " 
shape area. In the local inner concave mode, "I" and "bow" interfaces appear successively, and finally the " $\mathrm{M}$ " interface is formed.

(2) The mechanism of deformation characteristics under different explosive equivalent conditions is given by wave propagation, and the counterintuitive phenomenon is explained due to the reflection of circle shock wave by the bottom plate but there is no secondary reflection on the ceiling plate in the H-RP.

(3) The honeycomb structure can absorb most of the energy carried by a shock wave. In the energy absorption process, it is mainly the deformation energy of the cell single edges with $0.04 \mathrm{~mm}$ thickness (marked as SE) that plays a major role. However, there is a low proportion of the internal energy of the cell double edges with $0.08 \mathrm{~mm}$ thickness (marked as DE). It provides a new way to improve the energy-absorbed capacity of honeycombs.

(4) The honeycomb structure can effectively attenuate the stress peak of a shock wave. Besides, the buffering effect in the $X 1$ direction is better than that in the $X 2$ direction.

The model presented is not yet validated experimentally; therefore, it represents a preliminary numerical approach of the deformation behavior of honeycomb structures under direct and indirect explosion.

Author Contributions: Conceptualization, X.L.; methodology, Y.L.; software, X.L.; validation, Y.L. and F.L.; formal analysis, Y.L.; investigation, X.L.; resources, Y.L.; data curation, X.L. and Y.L.; writing-original draft preparation, X.L.; writing-review and editing, X.L., Y.L. and F.L.; visualization, X.L. and Y.L.; supervision, Y.L. and F.L.; project administration, Y.L.; funding acquisition, Y.L. and F.L.

Funding: This research was funded by the National Natural Science Foundation of China (grant numbers 11672329 and 11872376).

Acknowledgments: All authors thank Zhang Yuwu for helping to check the manuscript before submission.

Conflicts of Interest: The authors declare no conflict of interest.

\section{References}

1. Wierzbicki, T.; Abramowicz, W. On the Crushing Mechanics of Thin-Walled Structures. J. Appl. Mech. 1983, 50, 727-734. [CrossRef]

2. Baker, W.E.; Togami, T.C.; Weydert, J.C. Static and dynamic properties of high-density metal honeycombs. Int. J. Impact Eng. 1998, 21, 149-163. [CrossRef]

3. Qin, H.X.; Yang, D.Q.; Ren, C.H. Design method of lightweight metamaterials with arbitrary poisson's ratio. Materials 2018, 11, 1574. [CrossRef] [PubMed]

4. Gibson, L.J.; Ashby, M.F. Cellular Solids, Structural and Properties, 2nd ed.; Cambridge University Press: Cambridge, UK, 1999.

5. Miller, W.; Smith, C.W.; Evans, K.E. Honeycomb cores with enhanced buckling strength. Compos. Struct. 2011, 93, 1072-1077. [CrossRef]

6. Zhang, X.; Zhang, H.; Wen, Z. Experimental and numerical studies on the crush resistance of aluminum honeycombs with various cell configurations. Int. J. Impact Eng. 2014, 66, 48-59. [CrossRef]

7. Li, X.C.; Li, K.; Lin, Y.L.; Chen, R.; Lu, F.Y. Inserting stress analysis of combined hexagonal aluminum honeycombs. Shock Vib. 2016, 2016. [CrossRef]

8. Ashab, A.; Ruan, D.; Lu, G.; Bhuiyan, A.A. Finite element analysis of aluminum honeycombs subjected to dynamic indentation and compression loads. Materials 2016, 9, 162. [CrossRef]

9. Qiao, J.; Chen, C. In-plane crushing of a hierarchical honeycomb. Int. J. Solids Struct. 2016, 85-86, 57-66. [CrossRef]

10. Ruan, D.; Lu, G.X.; Wang, B.; Yu, T.X. In-plane dynamic crushing of honeycombs-a finite element study. Int. J. Impact Eng. 2003, 28, 161-182. [CrossRef]

11. Hu, L.L.; You, F.F.; Yu, T.X. Effect of cell-wall angle on the in-plane crushing behaviour of hexagonal honeycombs. Mater. Des. 2013, 46, 511-523. [CrossRef]

12. Papka, S.D.; Kyriakides, S. Experiments and full-scale numerical simulations of in-plane crushing of a honeycomb. Acta Mater. 1998, 46, 2765-2776. [CrossRef] 
13. Arash, F.; Christian, B.; Ralf, S. Numercial fracture analysis and model validation for disbonded honeycomb core sandwich composites. Compos. Struct. 2019, 210, 231-238.

14. Wang, Z.G.; Lu, Z.J.; Yao, S.; Zhang, Y.B.; Hui, D.; Feo, L. Deformation mode evolutional mechanism of honeycomb structure when undergoing a shallow inclined load. Compos. Struct. 2016, 147, 211-219. [CrossRef]

15. Wang, Z.G.; Liu, J.F.; Hui, D. Mechanical behaviors of inclined cell honeycomb structure subjected to compression. Compos. Part B Eng. 2017, 110, 307-314. [CrossRef]

16. Tounsi, R.; Markiewicz, E.; Zouari, B.; Chaari, F.; Haugou, G. Numerical investigation, experimental validation and macroscopic yield criterion of Al5056 honeycombs under mixed shear-compression loading. Int. J. Impact Eng. 2017, 108, 348-360. [CrossRef]

17. Sun, D.Q.; Zhang, W.H.; Wei, Y.B. Mean out-of-plane dynamic plateau stresses of hexagonal honeycomb cores under impact loadings. Compos. Struct. 2010, 92, 2609-2621.

18. Li, X.; Zhang, P.W.; Wang, Z.H.; Wu, G.Y.; Zhao, L.M. Dynamic behavior of aluminum honeycomb sandwich panels under air blast: Experiment and numerical analysis. Compos. Struct. 2014, 108, 1001-1008. [CrossRef]

19. Zhu, F.; Zhao, L.M.; Lu, G.X. Deformation and failure of blast loaded metallic sandwich panels—Experimental investigations. Int. J. Impact Eng. 2008, 35, 937-951. [CrossRef]

20. Li, S.Q.; Li, X.; Wang, Z.H.; Wu, G.Y.; Lu, G.X.; Zhao, L.M. Sandwich panels with layered graded aluminum honeycomb cores under blast loading. Compos. Struct. 2017, 173, 242-254. [CrossRef]

21. Jin, X.C.; Wang, Z.H.; Ning, J.G.; Xiao, G.S.; Liu, E.Q.; Shu, X.F. Dynamic response of sandwich structures with graded auxetic honeycomb cores under blast loading. Compos. Part B Eng. 2016, 106, 206-217. [CrossRef]

22. Dharmasena Kumar, P.; Wadley, H.N.; Xue, Z.Y.; Hutchinson John, W. Mechanical response of metallic honeycomb sandwich panel structures to high-intensity dynamic loading. Int. J. Impact Eng. 2008, 35, 1063-1074. [CrossRef]

23. Karagiozova, D.; Nurick, G.N.; Langdon, G.S. Behaviour of sandwich panels subject to intense air blasts-Part 2: Numerical simulation. Compos. Struct. 2009, 91, 442-445. [CrossRef]

24. Cui, X.; Zhao, L.; Wang, Z.; Zhao, H.; Fang, D. Dynamic response of metallic lattice sandwich structures to impulsive loading. Int. J. Impact Eng. 2012, 43, 1-5. [CrossRef]

25. Li, S.; Lu, G.; Wang, Z.; Zhao, L.; Wu, G. Finite element simulation of metallic cylindrical sandwich shells with graded aluminum tubular cores subjected to internal blast loading. Int. J. Mech. Sci. 2015, 96-97, 1-12. [CrossRef]

26. Edri, I.E.; Grisaro, H.Y.; Yankelevsky, D.Z. TNT equivalency in an internal explosion event. J. Hazard. Mater. 2019, 374, 248-257. [CrossRef] [PubMed] 